\title{
Incidence of atrial fibrillation and its effects on long-term follow-up outcomes in patients undergoing primary percutaneous coronary intervention for ST-elevation myocardial infarction
}

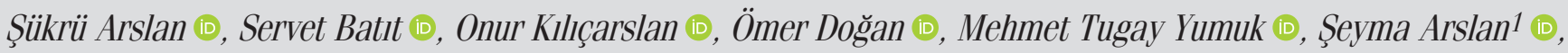 \\ Ísmail Haberal (i), Cüneyt Koçaş (D, Sait Mesut Doğan (D, Okay Abacı (i) \\ Department of Cardiology, İstanbul University-Cerrahpaşa Institude of Cardiology; İstanbul-Turkey \\ ${ }^{1}$ Republic of Turkey Ministry of Health
}

\section{ABSTRACT}

Objective: The incidence of atrial fibrillation (AF) in patients with ST segment elevation myocardial infarction (STEMI) varies between 7\% and $21 \%$, and most of these studies were in the thrombolytic era. However, the frequency of new-onset AF during the primary percutaneous coronary intervention (PCI) period is still unclear. We aimed to investigate the frequency of new-onset AF and its effects on long-term clinical events in patients undergoing primary $\mathrm{PCl}$.

Methods: A total of 1,603 patients who were diagnosed with STEMI and underwent primary PCI were included in the study. All the patients were monitored for at least 48 hours after the procedure. The primary endpoint of the study was defined as new-onset AF during hospitalization.

Results: The median follow-up period of our study was 44 months. New-onset AF developed in $85(6.1 \%)$ patients. CHADs-VASc $>2$, KILLIP > 2 , and left atrial diameter were found to be independent predictors for the development of new-onset AF. In the AF (+) group, the all-cause and in-hospital mortality rates were found to be significantly higher. New-onset AF development in patients with STEMI was detected as an independent predictor of in-hospital mortality.

Conclusion: In the era of primary percutaneous transluminal coronary angioplasty, new-onset AF rates were found to be lower than the literature data. In addition, new-onset AF was found to be a predictor of in-hospital mortality, and deaths occurred mostly in the early period. Therefore, close follow-up of these patients in the early period and re-evaluation in terms of AF burden when the patient becomes stable are important.

Keywords: new-onset atrial fibrillation, acute coronary syndrome, primary percutaneous coronary intervention

Cite this article as: Arslan Ş, Batıt S, Kılıçarslan O, Doğan Ö, Yumuk MT, Arslan Ş, et al. Incidence of atrial fibrillation and its effects on long-term follow-up outcomes in patients undergoing primary percutaneous coronary intervention for ST-elevation myocardial infarction. Anatol J Cardiol 2021; 25: 609-16.

\section{Introduction}

Atrial fibrillation is a common clinical arrhythmia that increases in frequency with age, diabetes, hypertension, and obesity, independent of structural heart disease $(1,2)$. Electrophysiological and metabolic changes in the myocardium because of myocardial ischemia or infarction produce silent or life-threatening arrhythmias. Although ventricular arrhythmias [accelerated idioventricular rhythm, ventricular tachycardia (VT), ventricular fibrillation (VF)] are frequently reported during acute coronary syndromes, atrial arrhythmias are also common (3). The incidence of AF in patients with ST segment elevation myocardial infarction (STEMI) varies between $7 \%-21 \%$, and the majority of these data are based on studies in the thrombolytic era (1). Recently, changes in treatment approaches and the development of early invasive treatment strategies have been thought to decrease these rates. Development of AF in STEMIs leads to hemodynamic deterioration owing to a high ventricular rate, irregular ventricular filling, and/or loss of atrial contribution to cardiac output. In addition, AF develop-

Address for Correspondence: Dr. Okay Abacı, İstanbul Üniversitesi-Cerrahpaşa Kardiyoloji Enstitüsü, Kardiyoloji Anabilim Dalı, İstanbul-Türkiye

Phone: +90 2124592000 E-mail: drokayabaci@hotmail.com

Accepted Date: 16.03.2021 Available Online Date: 26.08.2021

(C) Copyright 2021 by Turkish Society of Cardiology - Available online at www.anatoljcardiol.com DOI:10.5152/AnatolJCardiol.2021.26020 


\section{HIGHLIGHTS}

- In our study, we found that in-hospital new-onset atrial fibrillation (AF) rates were lower during the primary percutaneous transluminal coronary angioplasty era.

- We also found that the development of new-onset AF was associated with a four-fold increase in in-hospital mortality.

- In-hospital AF development did not cause a significant increase in long-term clinical events such as stroke and myocardial infarction in the primary percutaneous coronary intervention era.

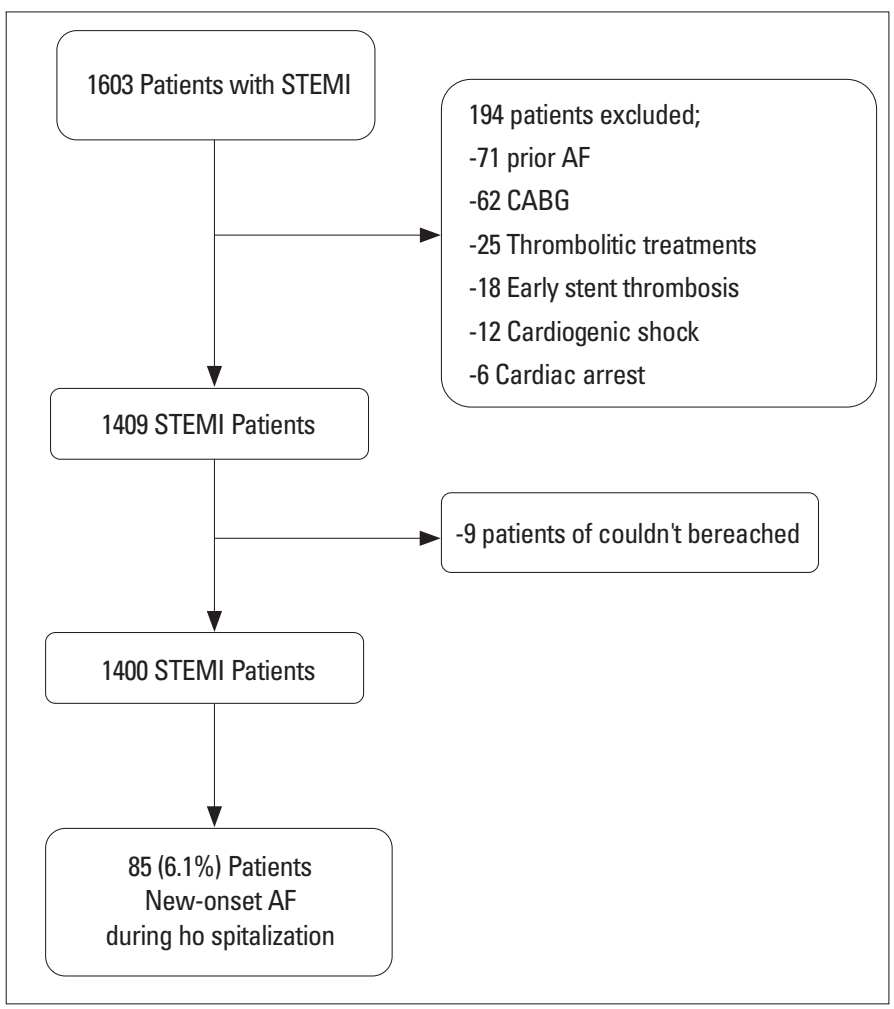

Figure 1. Trial flow chart

ment in patients with STEMI increases the risk of early stroke development than in those without AF. Therefore, AF development in patients with STEMI was associated with increased morbidity and mortality (4). In the current guidelines, anticoagulation therapy is recommended in this group of patients owing to the CHADs-VASc score; however, data on this condition are still unclear given the risks of bleeding (4). The studies on AF with STEMI were mostly conducted in 2010 and before. The majority of these studies were retrospective studies, and the patients were included in these studies after discharge with no early in-hospital $\operatorname{AF}(5,6)$.

In this study, we aimed to investigate the rates of new-onset $A F$, long-term anticoagulation ratio, and short- and long-term adverse clinical events during follow-up in patients with diag- nosed STEMI who were admitted to the emergency department and underwent primary percutaneous coronary intervention (PCI).

\section{Methods}

\section{Study population}

Our study was a cohort study. A total of 1,603 consecutive patients who were diagnosed with STEMI and underwent primary PCI between 2011 and 2018 at our cardiology center were analyzed. The exclusion criteria were patients with known atrial fibrillation, previous coronary artery bypass grafting, those with cardiogenic shock or early stage mechanical complications, at the end of the processing thrombolysis in myocardial infarction (TIMI) 0, 1 coronary blood flow, early stent thrombosis, treatment with thrombolytic therapy, severe valvular heart disease, thyroid diseases, and end-stage chronic organ failure (chronic obstructive pulmonary disease, chronic kidney disease, and chronic liver disease). A total of 1,400 patients were included in the study after exclusion. A flowchart of the patients is shown in Figure 1. All the patients gave their written informed consent, and the study was approved by the Local Ethics Commission (Ethics Committee of Istanbul University, Cerrahpaşa Cardiology Institute; 2.I.U.E.50.0.05.00/3).

\section{Study protocol}

The patients who presented with typical chest pain to the emergency unit of our hospital and had ST-segment elevation in two contiguous ECG leads (ST segment elevation in V2-V3 leads; $\geq 0.25 \mathrm{mV}$ in men under 40 years of age, $\geq 0.2 \mathrm{mV}$ in men over 40 years of age, or $\geq 0.15 \mathrm{mV}$ in women, and/or $\geq 0.1 \mathrm{mV}$ ST segment elevation in other leads) or had presumably new left bundlebranch block were diagnosed with STEMI (7). Loading doses of P2Y ${ }_{12}$ inhibitors $(600 \mathrm{mg}$ clopidogrel, $60 \mathrm{mg}$ prasugrel, or $180 \mathrm{mg}$ ticagrelor) and $300 \mathrm{mg}$ nonenteric-coated acetylsalicylic acid were given routinely to patients diagnosed with STEMI during their admission. All primer $\mathrm{PCl}$ procedures were performed by experienced interventional cardiologists using a femoral or radial approach. Patients undergoing $\mathrm{PCl}$ were administered 100 $\mathrm{IU} / \mathrm{kg}$ heparin during the procedure. The dose was reduced to 60 $\mathrm{IU} / \mathrm{kg}$ if the patient was given glycoprotein IIb/IIla inhibitors (GPIs). The choice of thrombus aspiration, stent type, and GPI usage were left to the preference of the operator. All the patients were monitored for at least 48 hours after the procedure by telemetry in the coronary intensive care unit. Patients who had complaints of palpitations during hospitalization were followed up with a 24-hour rhythm Holter monitor, and an ECG was recorded during palpitation. Major bleeding was defined using the Bleeding Academic Research Consortium (BARC) bleeding definitions: intracranial hemorrhage, intraocular compromising vision, overt bleeding plus hemoglobin drop $>5 \mathrm{~g} / \mathrm{dL}$, tamponade, bleeding requiring surgical or percutaneous intervention for control (excluding dental/nose/skin/hemorrhoids) or inotropes (BARC type 3A), any transfusion with overt bleeding, overt bleeding plus hemoglobin drop of 3 to $5 \mathrm{~g} / \mathrm{dL}$ (BARC type $3 \mathrm{~B}$ ) or fatal 
bleeding. All information on serious bleeding was identified with the diagnosis coded in a subsequent hospitalization during follow-up (8). Clinical data during follow-up were obtained from the medical records and recent clinical visits, using the insurance database system for death and stroke events and by contacting the patient and/or patient's relatives by phone.

\section{Atrial fibrillation ascertainment}

We defined AF using a conformation of the guidelines from the American College of Cardiology, American Heart Association, and European Heart Association (9). Patients with atrial flutter were considered to have $A F$, which was defined as the absence of $P$ waves, and atrial activity was described by fibrillatory waves and irregular time elapsing between two consecutive $R$ wave $(R-R)$ intervals. Atrial flutter on ECG recordings had to fulfill the following criteria; presence of regular $P$ waves with a rate of 250 to 350/min and regular or irregular R-R intervals. ECG diagnoses were assessed by two experienced cardiologists. Medical and/or DC cardioversion was administered to the patient who was found to have new-onset AF during hospitalization if there was no spontaneous termination within two hours.

\section{Endpoints}

The primary endpoint of the study was defined as new-onset AF during hospitalization. Major clinical outcomes (MACCEs) were defined as in-hospital mortality, all-cause mortality, myocardial infarction (MI), and cerebrovascular events (CVE). Other clinical outcomes were hospitalization for cardiac reasons and major bleeding.

\section{Statistical analysis}

Continuous variables were presented as means \pm standard deviation. Categorical variables were presented as frequencies (percentages). Normal distribution analysis of data was performed by the Shapiro-Wilk test. Student's t test was performed in cases of normally distributed data, and the Mann-Whitney $\mathrm{U}$ test was applied for abnormally distributed data. Categorical parameters were evaluated by Pearson's chi-squared test. Logistic regression (forward method) was used to devise a model of new-onset AF predictors and in-hospital mortality predictors. Predictors for major clinical outcomes were calculated by a multivariate analysis using parameters that had $\mathrm{p}$ values $<0.1$ in the univariate analysis. Long-term follow-up of major clinical outcomes and all-cause mortality were evaluated using Kaplan-Meier curves. The criterion for statistical significance in the analysis was $p \leq 0.05$. The Statistical Package for the Social Sciences version 21 (SPSS Inc., Chicago, Illinois, US) packet program was used for data analysis.

\section{Results}

\section{Clinical and demographical features and laboratory parameters}

The median follow-up period of our study was 44 months (six to 100 months). In our study, $85.5 \%$ of the patients were men, and the mean age of our study population was $58.6 \pm 11$ years. The door to balloon time was a median of 41 (six to 211) minutes. The median length of hospital stay was 12 (one to 62) days. Newonset $A F$, which was the primary endpoint of the study, developed in $85(6.1 \%)$ patients. Although conversion to spontaneous sinus rhythm was observed in $59(69.5 \%)$ patients, sinus rhythm was achieved with medical $(18.8 \%)$ and/or DC cardioversion (CV) $(11.7 \%)$ in $26(30.5 \%)$ patients. Amiodarone infusion was delivered for at least 24 hours to all the patients undergoing cardioversion. All of our study patients were in sinus rhythm at the time of discharge. Other cardiac arrhythmias, such as ventricular tachycardia/fibrillation $(8.0 \%)$ and $\mathrm{A}-\mathrm{V}$ block $(3.4 \%)$ were observed in $159(11.4 \%)$ of the patients during hospitalization.

The patients were divided into two groups: new-onset AF (+) and $A F(-)$. The demographic characteristics of the groups are given in Table 1. The average age of the AF (+) group was higher, and there were more women in this group $(p<0.001$ and $p<0.001$, respectively). In addition, the hypertension frequency was higher in the $\mathrm{AF}(+)$ group, and systolic arterial pressures were lower in this group ( $p=0.015$ and $p=0.053$, respectively). Active smoking and hyperlipidemia frequency were lower in the $A F(+)$ group ( $p<0.001$ and $p=0.034$, respectively). In the $A F(+)$ group, the frequency of KILLIP 3-4 patients was higher than that in the AF $(-)$ group ( $p=0.013$ ). In addition, the CHADs-VASc risk score was significantly higher in the $A F(+)$ group $(p<0.001)$. There was no difference between the groups in terms of MI types $(p=0.062$ ). The biochemical and echocardiographic characteristics of the groups are given in Table 2. Baseline Hb, LDL cholesterol, eGFR, and serum albumin levels were found to be significantly lower in the $A F(+)$ group than in the AF $(-)$ group $(p=0.002, p=0.001$, $p<0.001, p=0.002$, respectively). In addition, baseline serum creatinine, troponin, and ALT values were higher in the $A F(+)$ group $(p<0.001, p=0.035, p=0.005$, respectively). On baseline echocardiography, the mean left atrium diameter was significantly higher in the AF $(+)$ group $(p<0.001)$. It was found that $29.5 \%$ of the patients were given an oral anticoagulant agent as a discharge treatment. The majority of them were patients who underwent medical/DC CV. We also analyzed the study population according to whether MACCE developed [MACCE $(+)$ or MACCE (-)] (Table 3). The frequencies of DM, $\mathrm{HL}$, and prior MI were significantly higher in the MACCE $(+)$ group $(p=0.005, p<0.001, p<0.001$, respectively). The heart rate at the time of admission in the MACCE (+) group was found to be higher, but systolic blood pressure measurements were found to be lower $(p<0.001$ and $p<0.001$, respectively). In the MACCE (+) group, the door to balloon time was longer, and the contrast amount was higher ( $p=0.001$ and $p=0.009$, respectively).

Independent predictors of new-onset AF development were evaluated using the binary logistic regression model. The model consisting of anterior MI, CHADs-VASc $>2$, LVEF, KILLIP $>2$, basal creatinine, peak troponin, and LA diameter was evaluated as the best model (-2 log likelihood: 154.295; Nagelkerke R square: 0.34; chi-squared: 121.269 ; model $p<0.001)$. Accordingly, CHADs-VASc $>2$, KILLIP $>2$, and LA diameter were found to be independent predictors for the development of new-onset AF (Fig. 2a). 


\begin{tabular}{|c|c|c|c|}
\hline & $\begin{array}{c}A F(-) \\
(n=1315,93.9 \%)\end{array}$ & $\begin{array}{c}\operatorname{AF}(+) \\
(n=85,6.1 \%)\end{array}$ & $P$-value \\
\hline Age (years) & $58.1 \pm 11$ & $66.1 \pm 13$ & $<0.001$ \\
\hline Male, n (\%) & $1123(85.4)$ & $60(70.6)$ & $<0.001$ \\
\hline Hypertension, n (\%) & $463(35,2)$ & $41(48,2)$ & 0.015 \\
\hline Diabetes mellitus, n (\%) & $357(27.1)$ & $25(29.4)$ & 0.650 \\
\hline Hyperlipidemia, n (\%) & $457(34.8)$ & $20(23.5)$ & 0.034 \\
\hline Active smoking, n (\%) & $663(50.4)$ & $21(24.7)$ & $<0.001$ \\
\hline Previous CVA, n (\%) & $31(2.4)$ & $2(2.4)$ & 0.998 \\
\hline Previous MI, n (\%) & $216(16.4)$ & $20(23.5)$ & 0.090 \\
\hline Previous PCI, n (\%) & $263(20.0)$ & $22(25.9)$ & 0.192 \\
\hline PAD, n (\%) & $24(1.8)$ & $4(4.7)$ & 0.066 \\
\hline Chest pain, $\mathrm{h}$ & $3.6 \pm 4$ & $4.7 \pm 5$ & 0.371 \\
\hline Heart rate* & $78(25-164)$ & $78(35-160)$ & 0.967 \\
\hline $\begin{array}{l}\text { Systolic blood pressure } \\
(\mathrm{mm} \mathrm{Hg})^{*}\end{array}$ & $128.1 \pm 25$ & $120.9 \pm 28$ & 0.053 \\
\hline CHADs VASc score & $1.6 \pm 1$ & $2.7 \pm 2$ & $<0.001$ \\
\hline $\mathrm{CHADs}_{2}$ score & $1.0 \pm 1$ & $1.5 \pm 1$ & $<0.001$ \\
\hline Anterior MI, n (\%) & $553(42.1)$ & $27(31.8)$ & 0.062 \\
\hline \multicolumn{4}{|l|}{ Target vessel } \\
\hline LAD, n (\%) & $557(42.4)$ & $30(35.3)$ & 0.203 \\
\hline$C x, n(\%)$ & $237(18.0)$ & $13(15.3)$ & \\
\hline $\mathrm{RCA}, \mathrm{n}(\%)$ & $521(39.6)$ & $42(49.4)$ & \\
\hline \multicolumn{4}{|l|}{ KILLIP score } \\
\hline KILLIP I-II, n (\%) & $1235(93.9)$ & $74(87.1)$ & 0.013 \\
\hline KILLIP III-IV, n (\%) & $80(6.1)$ & 11 (12.9) & \\
\hline Contrast volume (mL) & $274.7 \pm 100$ & $307.2 \pm 100$ & 0.060 \\
\hline Cl-AKI, n (\%) & $260(19.8)$ & $21(24.7)$ & 0.267 \\
\hline \multicolumn{4}{|c|}{$\begin{array}{l}\text { *Median (min-max) } \\
\text { CHADs }_{2}^{-} \text {cardiac failure, hypertension, age, diabetes, stroke (doubled); CHADSVASC- } \\
\text { congestive heart failure, hypertension, age } \geq 75 \text { years (doubled), diabetes, stroke } \\
\text { (doubled), vascular disease, age } 65-74 \text { years, and sex category (female); CI-AKI - contrast } \\
\text { induced acute kidney injury, CVA - cerebrovascular accident; Cx - circumflex artery; LAD } \\
\text { - left anterior descending artery; MI - myocardial infarction; RCA - right coronary artery } \\
\text { PCI - percutaneous coronary intervention; PAD - peripheral artery disease }\end{array}$} \\
\hline
\end{tabular}

\section{Clinical outcomes}

In our study, MACCEs [death: 145 (10.4\%), in-hospital death: 59 (4.2\%), MI: 199 (14.2\%), SVO: $16(1.1 \%)]$ occurred in 351 $(25.1 \%)$ patients. Other clinical outcomes, such as hospitalization $(5.6 \%)$ with cardiac causes and major bleeding $(1.5 \%)$ occurred in $99(7.1 \%)$ patients. Evaluation of patients in terms of clinical outcomes according to AF development is given in Table 4. In the group with $A F$, all-cause mortality and in-hospital mortality were found to be significantly higher $(p=0.008$ and $p<0.001$, respectively). In addition, hospitalization rates with cardiac causes were significantly higher in the AF $(+)$ group $(p=0.003)$. There were no significant differences in the group with $A F$ in
Table 2. Baseline biochemical and echocardiographic characteristics of patients with STEMI according to development of atrial fibrillation

\begin{tabular}{|c|c|c|c|}
\hline & $\begin{array}{c}\operatorname{AF}(-) \\
(n=1315,93.9 \%)\end{array}$ & $\begin{array}{c}\operatorname{AF}(+) \\
(n=85,6.1 \%)\end{array}$ & $P$-value \\
\hline Hemoglobin (mg/dL) & $13.8 \pm 2$ & $13.1 \pm 2$ & 0.002 \\
\hline Leukocytes (/mm³) & $12471.2 \pm 4205$ & $12127.2 \pm 4640$ & 0.294 \\
\hline Neutrophil (/mm³) & $9051.8 \pm 4118$ & $8748.5 \pm 4295$ & 0.280 \\
\hline Lymphocytes $\left(/ \mathrm{mm}^{3}\right)$ & $2377.1 \pm 1534$ & $2409.6 \pm 1513$ & 0.983 \\
\hline Platelets $\left(x 10^{3} / \mathrm{mm}^{3}\right)$ & $255.5 \pm 95$ & $241.6 \pm 66$ & 0.177 \\
\hline Total cholesterol (mg/dL)* & $187(51-494)$ & $174(64-322)$ & 0.001 \\
\hline LDL cholesterol (mg/dL)* & $128(23-409)$ & 117 (31-709) & 0.001 \\
\hline HDL cholesterol $(\mathrm{mg} / \mathrm{dL})^{*}$ & $37(13-216)$ & $38(8-77)$ & 0.237 \\
\hline Triglycerides (mg/dL)* & $133(32-1785)$ & $121(47-431)$ & 0.058 \\
\hline Glucose $(\mathrm{mg} / \mathrm{dL})^{*}$ & $122(56-790)$ & $123(80-327)$ & 0.913 \\
\hline $\mathrm{HbA1c}(\%)$ & $6.72 \pm 1.8$ & $6.5 \pm 1.2$ & 0.808 \\
\hline Creatinine (mg/dL) & $0.96 \pm 0.4$ & $1.06 \pm 0.3$ & $<0.001$ \\
\hline eGFR (mL/min/1.73 m²) & $86.5 \pm 23$ & $72.7 \pm 22$ & $<0.001$ \\
\hline Peak troponin* & $3.48(0.1-35.0)$ & $4.45(0.2-30)$ & 0.035 \\
\hline $\mathrm{ALT}^{*}$ & $28(10-2395)$ & $33(10-654)$ & 0.005 \\
\hline $\mathrm{AST}^{*}$ & $48(10-1772)$ & 64 (10-1409) & 0.044 \\
\hline Albumin & $3.8 \pm 0.3$ & $3.7 \pm 0.4$ & 0.019 \\
\hline LVEF \% & $46.9 \pm 8$ & $44.9 \pm 10$ & 0.060 \\
\hline $\mathrm{LVd}(\mathrm{mm})$ & $49.7 \pm 5$ & $50.1 \pm 6$ & 0.509 \\
\hline IVS $(m m)^{*}$ & $11(7-24)$ & $11(9-15)$ & 0.075 \\
\hline $\mathrm{LA}(\mathrm{mm})$ & $37.5 \pm 5$ & $41.4 \pm 6$ & $<0.001$ \\
\hline \multicolumn{4}{|c|}{$\begin{array}{l}\text { *Median (min-max) } \\
\text { ALT - alanine aminotransferase; AST - aspartate aminotransferase; eGFR - estimated } \\
\text { glomerular filtration rate; HbA1c - hemoglobin A1c; HDL - high-density lipoprotein; IVS - } \\
\text { interventricular septum thickness; LA - left atrium diameter; LDL - low-density lipoprotein; } \\
\text { LVd - left ventricular diastolic diameter; LVEF - left ventricular ejection fraction }\end{array}$} \\
\hline
\end{tabular}

terms of MACCE, MI, CVE, and major bleeding ratios $(p=0.487$, $p=0.191, p=0.976, p=0.072$, respectively). The predictors of inhospital death were evaluated using a binary logistic regression model. The regression model consisting of anterior $\mathrm{MI}$, baseline glucose levels, VT/VF development, AF development, and LVEF was evaluated as the best model (-2 log likelihood: 124.295; Nagelkerke R square: 0.39; chi-square: 124.269; model $p<0.001$ ). According to this model, baseline glucose level [odds ratio $(O R)=1.008,95 \%$ confidence interval (CI) 1.004-1.011, $p<0.001$, in-hospital VT/VF development (OR=3.450, 95\% Cl 1.618-7.360, $\mathrm{p}<0.001)$, new-onset AF development (OR=4.022, 95\% Cl 1.7329.337, $\mathrm{p}=0.001$ ), and LVEF (OR=0.862, 95\% CI 0.830-0.895, $\mathrm{p}<0.001$ ) were found to be independent predictors in terms of in-hospital death (Fig. 2b). According to AF development, Kaplan-Meier curves for MACCE and all-cause death are given in Figure 3.

\section{Multivariable analysis}

In our study, MACCE predictors were analyzed by a Cox regression multivariable model (Fig. 2c). For the long-term follow-up, a multivariable proportional Cox regression analysis 


\begin{tabular}{|c|c|c|c|}
\hline & $\begin{array}{c}\text { MACCE }(-) \\
(n=1049,74.9 \%)\end{array}$ & $\begin{array}{c}\text { MACCE }(+) \\
(n=351,25.1 \%)\end{array}$ & $P$-value \\
\hline Age (years) & $58.1 \pm 11$ & $66.1 \pm 13$ & 0.008 \\
\hline Male, n (\%) & $886(84.5)$ & $297(84.6)$ & 0.945 \\
\hline Hypertension, n (\%) & $336(34.9)$ & $138(39.3)$ & 0.135 \\
\hline Diabetes mellitus, $\mathrm{n}(\%)$ & $266(25.4)$ & $116(33.0)$ & 0.005 \\
\hline Hyperlipidemia, n (\%) & $321(30.6)$ & $156(44.4)$ & $<0.001$ \\
\hline Active smoking, $\mathrm{n}(\%)$ & $176(24.6)$ & $175(25.6)$ & 0.665 \\
\hline Previous CVA, n (\%) & $17(1.6)$ & $16(4.6)$ & $<0.001$ \\
\hline Previous MI, n (\%) & $154(14.7)$ & $82(23.4)$ & $<0.001$ \\
\hline Previous PCI, n (\%) & $191(18.2)$ & $94(26.8)$ & 0.001 \\
\hline Chest pain, $\mathrm{h}$ & $3.3 \pm 3$ & $4.3 \pm 5$ & 0.817 \\
\hline Door to balloon (min) & $46.9 \pm 30$ & $54.1 \pm 36$ & 0.001 \\
\hline Heart rate* & $76(25-164)$ & $80(30-160)$ & $<0.001$ \\
\hline $\begin{array}{l}\text { Systolic blood pressure } \\
(\mathrm{mm} \mathrm{Hg})^{*}\end{array}$ & $129.8 \pm 23$ & $120.9 \pm 29$ & $<0.001$ \\
\hline CHADs VASc score $>2$ & $256(24.7)$ & $132(39.2)$ & $<0.001$ \\
\hline Anterior MI, n (\%) & $425(40.5)$ & $155(44.2)$ & 0.230 \\
\hline KILLIP score $>2$ & $32(3.1)$ & $59(16.8)$ & $<0.001$ \\
\hline In-hospital AF & $61(5.8)$ & $24(6.8)$ & 0.487 \\
\hline In-hospital VT/VF & $74(7.1)$ & $38(10.8)$ & 0.024 \\
\hline $\begin{array}{l}\text { Discharged } \\
\text { anticoagulation }\end{array}$ & $26(2.5)$ & $9(2.9)$ & 0.928 \\
\hline Contrast volume $(\mathrm{mL})$ & $269.7 \pm 99$ & $290.3 \pm 104$ & 0.009 \\
\hline Hemoglobin (mg/dL) & $13.8 \pm 2$ & $13.7 \pm 2$ & 0.288 \\
\hline Leukocytes (/mm³) & $12363.7 \pm 3994$ & $12681.7 \pm 4678$ & 0.338 \\
\hline LDL cholesterol (mg/dL) & $129.9 \pm 37$ & $126.2 \pm 54$ & 0.004 \\
\hline Triglycerides $(\mathrm{mg} / \mathrm{dL})^{*}$ & $131(32-936)$ & $135(33-1785)$ & 0.616 \\
\hline Glucose $(\mathrm{mg} / \mathrm{dL})^{*}$ & $119(56-495)$ & $128(62-616)$ & $<0.001$ \\
\hline Creatinine $(\mathrm{mg} / \mathrm{dL})$ & $0.93 \pm 0.3$ & $1.07 \pm 0.7$ & $<0.001$ \\
\hline Peak troponin* & $3.32(0.1-35.0)$ & $4.29(0.1-30)$ & 0.003 \\
\hline LVEF \% & $47.9 \pm 8$ & $42.9 \pm 9$ & $<0.001$ \\
\hline
\end{tabular}

*Median (min-max)

AF - atrial fibrillation; CHADs VASc - congestive heart failure, hypertension, age $\geq 75$ (doubled), diabetes, stroke (doubled), vascular disease, age 65-74, and sex category (female); CVA - cerebrovascular accident; MI - myocardial infarction; LDL - low-density lipoprotein; LVEF - left ventricular ejection fraction; $\mathrm{PCI}$ - percutaneous coronary intervention; MACCE - major cardiac and cerebrovascular events (death + MI + CVA); VT ventricular tachycardia; VF - ventricular fibrillation

model was performed for MACCE development according to the following variables: age, male sex, DM, HL, peripheral artery disease, prior Ml, door to balloon time, systolic blood pressure, KILLIP score $>2$, baseline glucose level, baseline creatinine level, LVEF, new-onset AF, and in-hospital VT/VF. HL [hazard ratio $(\mathrm{HR})=1.607,95 \% \mathrm{Cl} 1.239-2.085, \mathrm{p}<0.001)$, door to balloon time (HR=1.004, 95\% Cl 1.000-1.007, $\mathrm{p}=0.043$ ), baseline systolic blood
Table 4. Clinical outcomes of patients with STEMI according to development of atrial fibrillation

\begin{tabular}{|lccc|}
\hline & AF (-) n=1315 & AF (+) n=85 & P-value \\
\hline Death, n (\%) & $129(9.8)$ & $16(18.8)$ & 0.008 \\
MI, n (\%) & $191(14.5)$ & $8(9.4)$ & 0.191 \\
CVA, n (\%) & $15(1.1)$ & $1(1.2)$ & 0.976 \\
MACCE, n (\%) & $327(24.9)$ & $24(28.2)$ & 0.487 \\
In-hospital death, n (\%) & $49(3.7)$ & $10(11.8)$ & $<0.001$ \\
In-hospital VT/VF, n (\%) & $95(7.2)$ & $17(20.0)$ & $<0.001$ \\
Hospitalization, n (\%) & $68(5.2)$ & $11(12.9)$ & 0.003 \\
Major bleeding, n (\%) & $18(1.4)$ & $2(2.3)$ & 0.072 \\
\hline $\begin{array}{l}\text { AF - atrial fibrillation; CVA - cerebrovascular accident; MACCE - major cardiac and } \\
\text { cerebrovascular events (death + MI + CVA); MI - myocardial infarction; VT - ventricular } \\
\text { tachycardia; VF - ventricular fibrillation; STEMI - ST elevation myocardial infarction }\end{array}$ \\
\hline
\end{tabular}

pressure (HR=0.993, 95\% $\mathrm{Cl} 0.988-0.998, \mathrm{p}=0.010)$, KILLIP score $>2$ (HR=2.459, 95\% Cl 1.678-3.603, $\mathrm{p}<0.001)$, baseline glucose level (HR=1.003, 95\% Cl 1.001-1.005, $\mathrm{p}=0.001)$, baseline creatinine level (HR=1.323, 95\% Cl 1.136-1.541, $\mathrm{p}<0.001)$, and LVEF ( $\mathrm{HR}=0.956,95 \% \mathrm{Cl} 0.942-0.970, \mathrm{p}<0.001$ ) were determined to be independent predictors for MACCE development.

\section{Discussion}

The most comprehensive data on new-onset $\mathrm{AF}$ in patients with STEMI were derived from a systemic review of approximately 20 studies conducted by Schmitt et al. (1). In the review, it was reported that the studies on the subject were mostly obtained from data belonging to the thrombolytic era (patient inclusion from 2007 and before). According to this review, it is reported that the frequency of AF during acute $\mathrm{MI}$ was between $6.8 \%$ and $21 \%$. In addition, as a result of the review, it was reported that AF development based on AMI increased in-hospital and long-term mortality. In a multicenter and retrospective study by Garg et al. (6), AF was accompanied by STEMI in $8.7 \%$ of patients and was linked to increased in-hospital mortality, hospitalization time, and stroke. However, the method used in STEMI treatment and the long-term clinical outcomes of the study were unclear and included known AF in the study population. In a study published in 2020 by Zhang et al. (10), 750 patients with ACS (42.5\% STEMI, 18.3\% non-STEMI, and $39.2 \%$ unstable angina pectoris) were enrolled. They found that an $\mathrm{AF}$ attack developed in $6.7 \%$ of patients during a four-year follow-up. In the long-term follow-up, NT-proBNP, creatinine kinase MB, and LVEF were detected as AF predictors. In this study, in-hospital AF prevalence and long-term clinical outcome data were not reported (10). Lau et al. (5) included 607 patients with STEMI and determined new-onset $\mathrm{AF}$ in $13.7 \%$ of patients during 60 months of follow-up. In addition, women were found to be more prevalent in the group with $A F(+)$, and LVEF was found to be less prevalent in the study. However, the rates of new-onset AF were not indicated in-hospital and only the new-onset AF rates in follow-up after discharge of the patients were given. In addition, mortality data were not available (5). Siu et al. (4) have found the 


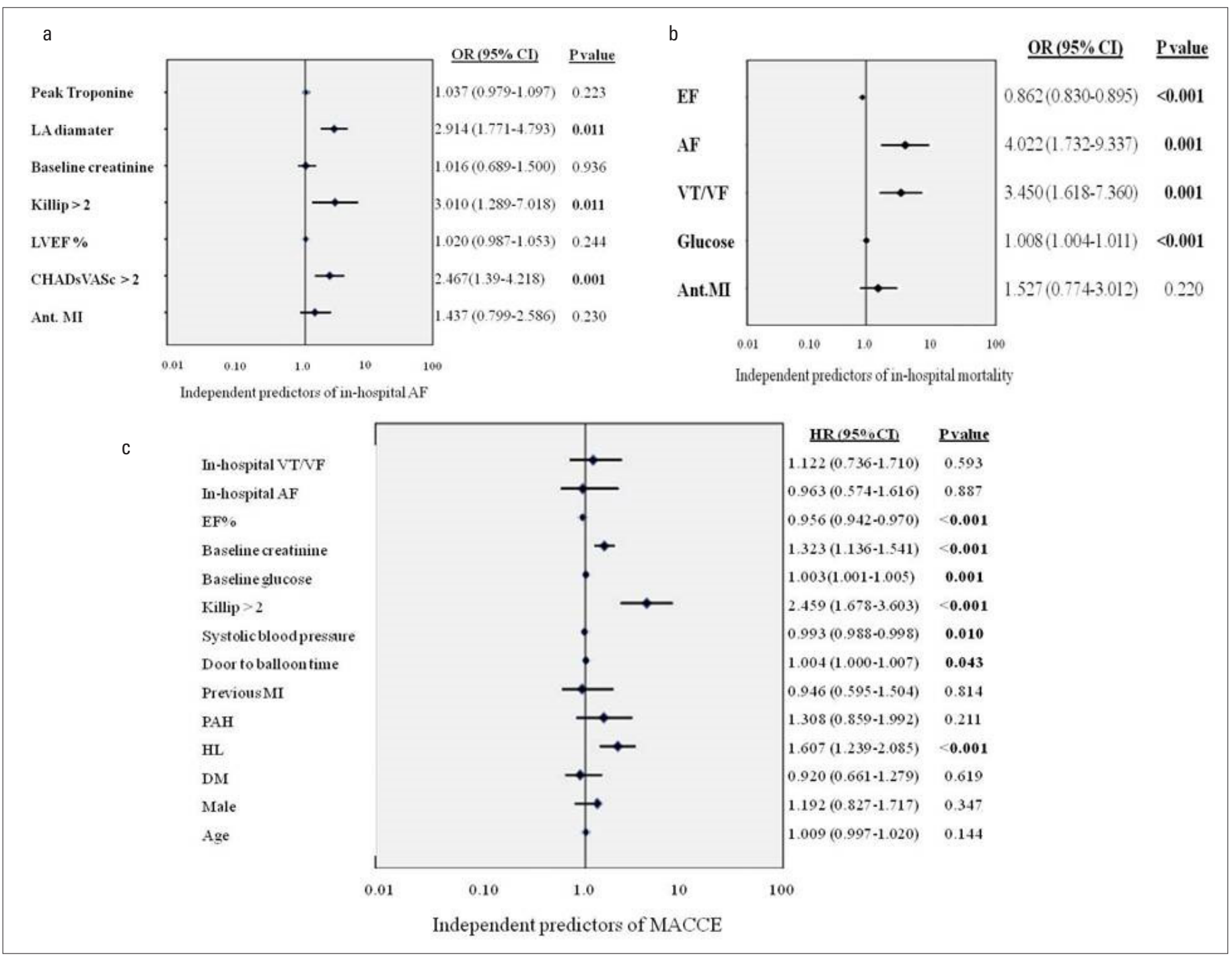

Figure 2. Forest plots displaying independent predictors of in-hospital atrial fibrillation (a), in-hospital mortality (b), and major cardiac and cerebrovascular events (c)

rate of in-hospital new-onset AF to be $13.7 \%$ in 504 patients with acute inferior $\mathrm{MI}$ with a previously unknown diagnosis of AF. The mean age and frequency of women were found to be higher in the group with AF. Mortality rates were similar at the one-year followup, but stroke was observed more frequently in the group with $A F$ $(+)$. However, only $30 \%$ of patients who developed AF at discharge were prescribed oral anticoagulant agents. Current guidelines recommend that anticoagulant treatment should be given in the long-term follow-up according to the CHADs-VASc stroke score and the HAS-BLEED bleeding score in patients with new-onset AF with STEMI (9). However, most of the literature studies do not have sufficient data on this subject. An oral anticoagulant agent was administered to only $30 \%$ of the patients who developed new-onset AF during hospitalization for STEMI (4).

Age, hypertension, male sex, and CAHDs-VASc and KILLIP scores have been extensively studied as AF predictors and are known to be significant risk factors (11-13). Similar results were encountered in our study, except the female sex ratio, which was found to be higher in the group with $A F(+)$. In addition, CHADs and CHADs-VASc scores, which are used to predict thromboembolic events in patients with $A F$, have been recently investigated for their effects on mortality in ACS. The CHADsVASc score especially has been reported to predict in-hospital and long-term mortality in patients with ACS $(14,15)$. The CHADs-VASc score also was found to be an important predictor of in-hospital mortality in our study.

In our study, the incidence of new-onset AF was found to be lower than the literature data. Similar to the literature, in-hospital mortality and all-cause mortality were found to be higher in patients with AF. Kaplan-Meier survival analyses show that the increase in all-cause mortality is mainly driven by in-hospital deaths. In addition, no significant increase in the frequency of stroke or MI was observed in our study. We think that this situation can be explained in two ways. First, the inclusion of patients who underwent primary $\mathrm{PCl}$, the administration of dual antiplatelet agents for at least one year, high-dose statin, and effec- 

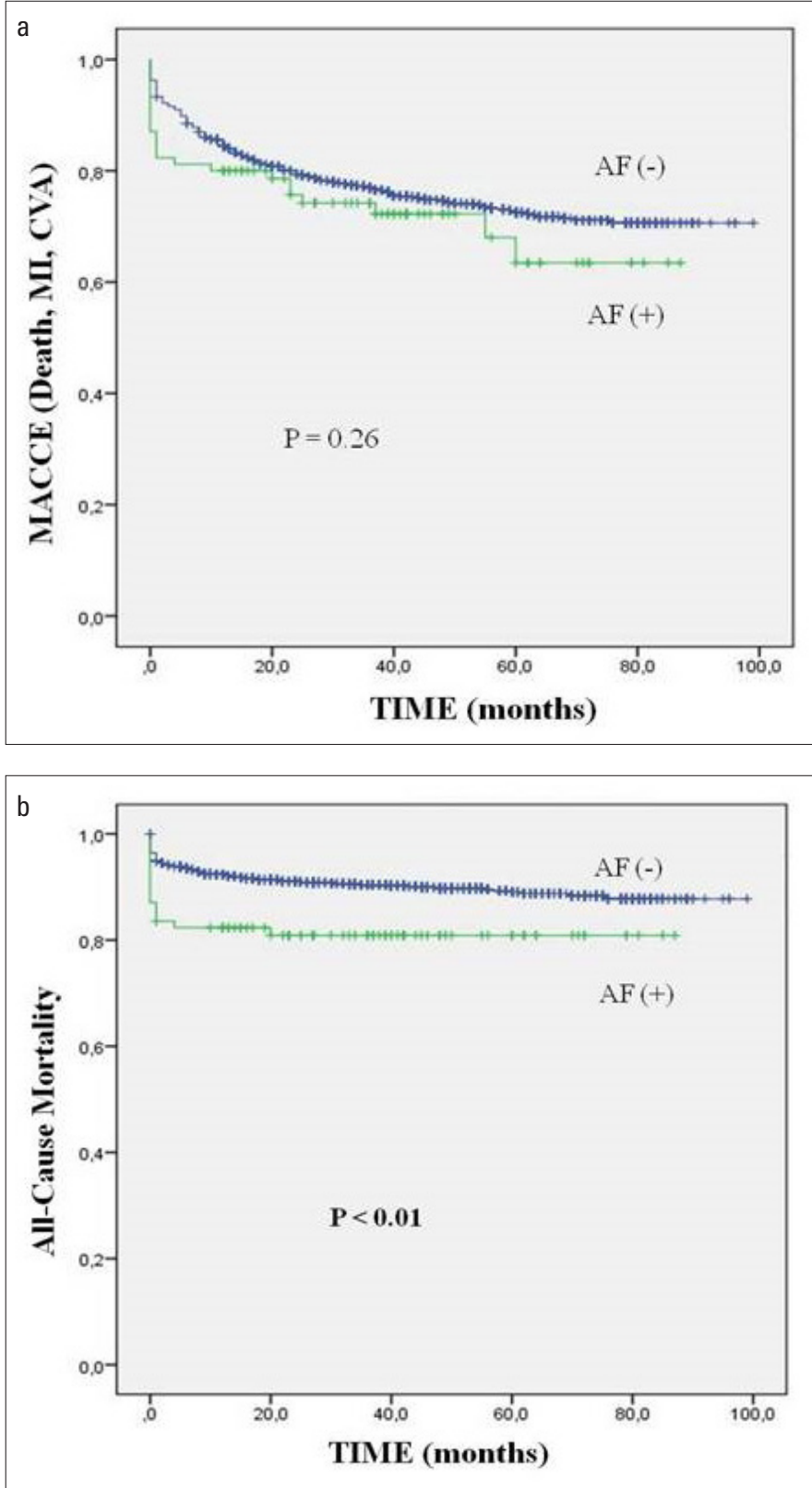

Figure 3. Kaplan-Meier cumulative event curves for all-cause death and major cardiac and cerebrovascular events in long-term follow-up of patients with and without in-hospital atrial fibrillation

tive dose ACE-I treatment, and the addition of an anticoagulant agent to approximately one-third of patients with AF may affect the frequencies of stroke and MI. Second, the absence of known AF diagnoses in the patients included in the study, the inclusion of only patients with in-hospital AF, and all patients being in sinus rhythm at the time of discharge may have affected the rates. When focusing on Kaplan-Meier curves, we see that inhospital mortality rates in patients with AF affect long-term data. This situation suggests that the effects of in-hospital AF on longterm mortality decreased when the patient was discharged and stabilized. The mechanism of the increase in the incidence of atrial arrhythmias in STEMI is still unknown. However, atrial ischemia or infarction, acute hypoxia or hypokalemia, pericar- dial inflammation, increased LV diastolic pressure and left atrial pressure, hemodynamic impairment because of LV dysfunction, and autonomic regulation are thought to lead to $\mathrm{AF}$ development (16). As mentioned above, in-hospital AF that develops based on STEMI has many causes, and most of them are conditions that can be eliminated in the future with early intervention in patients with STEMI. Therefore, patients with STEMI who develop AF should be followed up closely in the early period, and when the situation stabilizes in the long term, risk assessment can be performed again and evaluated in terms of anticoagulation as a treatment option.

\section{Study limitations}

There were several limitations and uncertainties in the literature data, such as patient admissions in 2013 and before, thrombolytic therapy era, follow-up data limited to one year, patients with known AF were not excluded from the study, and the rates of inhospital AF and anticoagulant treatment rates after discharge on this subject were not determined. In our study, unlike the literature, analyses were performed only according to patients with newonset AF in-hospital, and primary $\mathrm{PCl}$ was applied to all patients. In addition, in-hospital mortality and long-term major adverse event data were noted in our study.

The facts that the study was single-center, and telemetry follow-up was limited to the first 48 hours constituted important limitations of our study. Other limitations were that brain natriuretic peptide monitoring could not be performed (insurance reimbursement problems), and scores indicating the severity of coronary artery disease (SYNTAX, ACC lesion classification, etc.) were not used.

\section{Conclusion}

In our study, we found that in-hospital new-onset AF rates were lower during the primary PTCA era. We also found that the development of new-onset AF was associated with a four-fold increase in in-hospital mortality. Another important result of our study was that in-hospital AF development did not cause a significant increase in long-term clinical events such as stroke and myocardial infarction. Therefore, we believe that it would be appropriate to closely follow new-onset AF during the STEMI process in the early period, but re-evaluate them in terms of long-term treatments when the condition becomes stable. Investigating this situation with actual multi-center studies on the subject will remove the uncertainties.

\section{Conflict of interest: None declared.}

Peer-review: Externally peer-reviewed.

Author contributions: Concept - Şükrü Arslan, 0.A.; Design - Şükrü Arslan, Şeyma Arslan, O.A.; Supervision - Şükrü Arslan, S.M.D.; Fundings - Ö.D., M.T.Y.; Materials - S.B., O.K.; Data collection \&/or processing - S.B., O.K., Ö.D., M.T.Y.; Analysis \&/or interpretation - Şeyma Arslan; Literature search - I.H., C.K.; Writing - Şükrü Arslan, S.B., O.K., Ö.D., M.T.Y., Şeyma Arslan, I.H., C.K., S.M.D., O.A.; Critical review - I.H., C.K., S.M.D., O.A. 


\section{References}

1. Schmitt J, Duray G, Gersh BJ, Hohnloser SH. Atrial fibrillation in acute myocardial infarction: a systematic review of the incidence, clinical features and prognostic implications. Eur Heart J 2009; 30: 1038-45. [Crossref]

2. Staerk L, Sherer JA, Ko D, Benjamin EJ, Helm RH. Atrial Fibrillation: Epidemiology, Pathophysiology, and Clinical Outcomes. Circ Res 2017; 120: 1501-17. [Crossref]

3. Gorenek B, Blomström Lundqvist C, Brugada Terradellas J, Camm $A J$, Hindricks $G$, Huber $K$, et al. Cardiac arrhythmias in acute coronary syndromes: position paper from the joint EHRA, ACCA, and EAPCI task force. Europace 2014; 16: 1655-73. [Crossref]

4. Siu CW, Jim MH, Ho HH, Miu R, Lee SW, Lau CP, et al. Transient atrial fibrillation complicating acute inferior myocardial infarction: implications for future risk of ischemic stroke. Chest 2007; 132: 44-9. [Crossref]

5. Lau KK, Chan PH, Yiu KH, Chan YH, Liu S, Chan KH, et al. Roles of the CHADS2 and CHA2DS2-VASc scores in post-myocardial infarction patients: Risk of new occurrence of atrial fibrillation and ischemic stroke. Cardiol J 2014; 21: 474-83. [Crossref]

6. Garg L, Agrawal S, Agarwal M, Shah M, Garg A, Patel B, et al. Influence of Atrial Fibrillation on Outcomes in Patients Who Underwent Primary Percutaneous Coronary Intervention for ST-Segment Elevation Myocardial Infarction. Am J Cardiol 2018; 121: 684-9. [Crossref]

7. Thygesen K, Alpert JS, White HD; Joint ESC/ACCF/AHA/WHF Task Force for the Redefinition of Myocardial Infarction. Universal definition of myocardial infarction. Eur Heart J 2007; 28: 2525-38. [Crossref]

8. Mehran R, Rao SV, Bhatt DL, Gibson CM, Caixeta A, Eikelboom J, et al. Standardized bleeding definitions for cardiovascular clinical trials: a consensus report from the Bleeding Academic Research Consortium. Circulation 2011; 123: 2736-47. [Crossref]

9. Fuster $V$, Rydén $L E$, Cannom DS, Crijns $H J$, Curtis $A B$, Ellenbogen $K A$, et al.; American College of Cardiology/American Heart
Association Task Force on Practice Guidelines; European Society of Cardiology Committee for Practice Guidelines; European Heart Rhythm Association; Heart Rhythm Society. ACC/AHA/ESC 2006 Guidelines for the Management of Patients with Atrial Fibrillation: a report of the American College of Cardiology/American Heart Association Task Force on Practice Guidelines and the European Society of Cardiology Committee for Practice Guidelines (Writing Committee to Revise the 2001 Guidelines for the Management of Patients With Atrial Fibrillation): developed in collaboration with the European Heart Rhythm Association and the Heart Rhythm Society. Circulation 2006; 114: e257-354.

10. Zhang H, Dong P, Yang X, Du L, Wang K, Yan P, et al. Prognostic indicators of new onset atrial fibrillation in patients with acute coronary syndrome. Clin Cardiol 2020; 43: 647-51. [Crossref]

11. Gorenek B, Kudaiberdieva G. Arrhythmic emergencies in ICCU. Minerva Med 2013; 104: 383-90.

12. Krahn AD, Manfreda J, Tate RB, Mathewson FA, Cuddy TE. The natural history of atrial fibrillation: incidence, risk factors, and prognosis in the Manitoba Follow-Up Study. Am J Med 1995; 98: 476-84. [Crossref]

13. Liu XK, Jahangir A, Terzic A, Gersh BJ, Hammill SC, Shen WK. Ageand sex-related atrial electrophysiologic and structural changes. Am J Cardiol 2004; 94: 373-5. [Crossref]

14. Luo J, Xu S, Li H, Li Z, Liu B, Qin X, et al. Long-term impact of newonset atrial fibrillation complicating acute myocardial infarction on heart failure. ESC Heart Fail 2020; 7: 2762-72. [Crossref]

15. Chua SK, Lo HM, Chiu CZ, Shyu KG. Use of CHADS and CHA DS VASc scores to predict subsequent myocardial infarction, stroke, and death in patients with acute coronary syndrome: data from Taiwan acute coronary syndrome full spectrum registry. PLoS One 2014; 9: e111167.

16. Keskin K, Sezai Yıldız S, Çetinkal G, Aksan G, Kilci H, Çetin Ş, et al. The Value of CHA2DS2VASC Score in Predicting All-Cause Mortality in Patients with ST-Segment Elevation Myocardial Infarction Who Have Undergone Primary Percutaneous Coronary Intervention. Acta Cardiol Sin 2017; 33: 598-604. 